\title{
Performance assessment in the maternity pathway in Tuscany region
}

\author{
Sabina Nuti, Anna Bonini, Anna Maria Murante and Milena Vainieri
}

Scuola Superiore Sant'Anna, Management and Health Laboratory, Pisa, Italy

E-mail: snuti@sssup.it

\begin{abstract}
Summary
The paper describes the performance measurement system of the maternity pathway used in Tuscany by health care professionals, general managers and regional policy-makers. This system uses 19 indicators grouped in six dimensions: population's state of health; compliance with regional guidelines; efficiency and financial performance; clinical and health assessment; patient satisfaction; and employees' satisfaction. The results are represented on a spider diagram that summarizes the results on the different dimensions. The Tuscan performance measurement system of the maternity pathway has been used to identify best practice within, and their adoption throughout, the Tuscan public health care system.
\end{abstract}

\section{Introduction}

Sixty-one years ago, in 1948, both the World Health Organization (WHO) and the United Nations (UN) recognized the importance of maternal infant care. The WHO consider it as one of their main functions 'to promote maternal and child health and welfare'. ${ }^{1}$ The UN secured in the Universal Declaration of Human Rights the obligation to provide 'special care and assistance' for mothers and children. ${ }^{2}$ The primary health care movement launched at Alma-Ata in 1978 also recognized the importance of maternal infant care. The topic received renewed attention in the last decade when it was identified as one of the goals of the Millennium Development Goals as an integral part of poverty reduction. ${ }^{3}$ The WHO report of 2005 emphasized that: 'Public health programmes need to work together so that all families have access to a continuum of care that extends from pregnancy (and even before), through childbirth and on into childhood, instead of the often fragmented services available at present'. ${ }^{4}$

In Italy, National Health Plan (NHP) 1998-2001 identified a strategy of developing maternal and infant care as a strategic pathway, indicating actions required to achieve the strategic objectives. ${ }^{5}$ Following the 2000

Sabina Nuti MBA, Professor of Economics and Public Administration, Director of Management and Health Laboratory, Scuola Superiore Sant'Anna, Piazza Martiri della Libertà, 33-56125 Pisa, Italy.

Anna Bonini MS, Management and Health Laboratory, Scuola Superiore Sant'Anna, Piazza Martiri della Libertà, 33-56125 Pisa, Italy.

Anna Maria Murante MS, Management and Health Laboratory, Scuola Superiore Sant'Anna, Piazza Martiri della Libertà, 33-56125 Pisa, Italy.

Milena Vainieri MS, Management and Health Laboratory, Scuola Superiore Sant'Anna, Piazza Martiri della Libertà, 33-56125 Pisa, Italy.
Ministry of Health's adoption of the 'maternal and infant care objective project', regions emphasized the importance of maternal and infant care in their Regional Health Plans (RHP). Since 1998, the RHPs of Tuscany ${ }^{6-8}$ have sought to implement the national strategy and achieve national objectives. Two regional laws (DGR n. 555 and the DGR n. 784 both of 2004) $)^{9,10}$ stipulated guidelines for the Tuscan Local Health Authorities (LHAs) for the maternity pathway, and actions to be implemented, to renew and develop the regional network of maternity and infant care. These laws resulted in numerous training initiatives and organizational changes.

This paper aims to describe the performance measurement system of the maternity pathway (PMSMP) adopted by Tuscany region from 2004 in order to assess and monitor its LHAs and Teaching Hospitals (THs). ${ }^{11,12}$

\section{Conceptual framework}

The PMSMP was developed using lessons from the many performance measurement systems that have been developed over the last 20 years, ${ }^{13-15}$ in particular from multidimensional systems already used in health care ${ }^{16-18}$ and the model of the Balanced Scorecard. ${ }^{19-21}$ One of the lessons was the importance of developing the PMSMP in close collaboration with health care professionals and managers. ${ }^{22-25}$

\section{The multidimensional evaluation system for the} maternal infant care pathway

The Tuscan region has a low birth rate, although there has been a small increase since 1995. In 2005, there were 31,433 deliveries, $98 \%$ of which were in a public hospital, with a birth rate of 8.7 newborns per 1000 inhabitants, lower than the national one that was 9.5 per 1000 inhabitants. 
The PMSMP consists of six dimensions of assessment (the letter is used to indicate each dimension):

(a) Population health, such as the infant mortality rate (A1);

(b) Regional health system, to guarantee equity of access throughout the region, but also points recommended by WHO such as Breastfeeding (B6.1), Continuity of care (B6.2), Humanity of care (B6.5);

(c) Quality, appropriateness, effectiveness and managing supply to match demand; e.g. Nullipar Terminal Single Vertex (NTSV) caesarean rate (C7.1) for women at the first delivery with the minimum of 38 weeks of pregnancy, no twins and in vertex position;

(d) Patient satisfaction, the experience of women who have given birth on care and help provided throughout the care pathway (from the prenatal to the postnatal phase);

(e) Staff satisfaction, results of surveys on the satisfaction level of staff who deliver care with their working conditions and management by the LHA;

(f) Efficiency and financial performance, such as the number of deliveries per gynaecologist and number of deliveries per obstetrician.

In order to display performance by each dimension, a spider chart was used with assessment on each indicator classified into the six dimensions, being divided into five bands with different colours (with scores in parentheses):

(1) Dark green (between 4 and 5), excellent performance (achieving the target);

(2) Light green (between 3 and 4), good performance;

(3) Yellow (between 2 and 3), average performance and ample scope for improvement;

(4) Orange (between 1 and 2), poor performance that can and must be improved;

(5) Red (below 1), failing performance that can and must be improved urgently.

An LHA with a high score on an indicator for each dimension will be displayed as close to the centre (dark green) and one with a low score will be displayed as far from the centre (red) (Figure 1).

\section{Selection of indicators}

Performance on each dimension of the spider diagram is the sum of scores across a 'tree' of indicators (Table 1). In 2004 indicators were selected from those used in other systems such as Ontario (Canada), UK and USA. ${ }^{26,27}$ These were presented and discussed with health care professionals and managers throughout the region in meetings, focus groups, seminars and in a consensus conference. They were considered in terms of the availability of data and

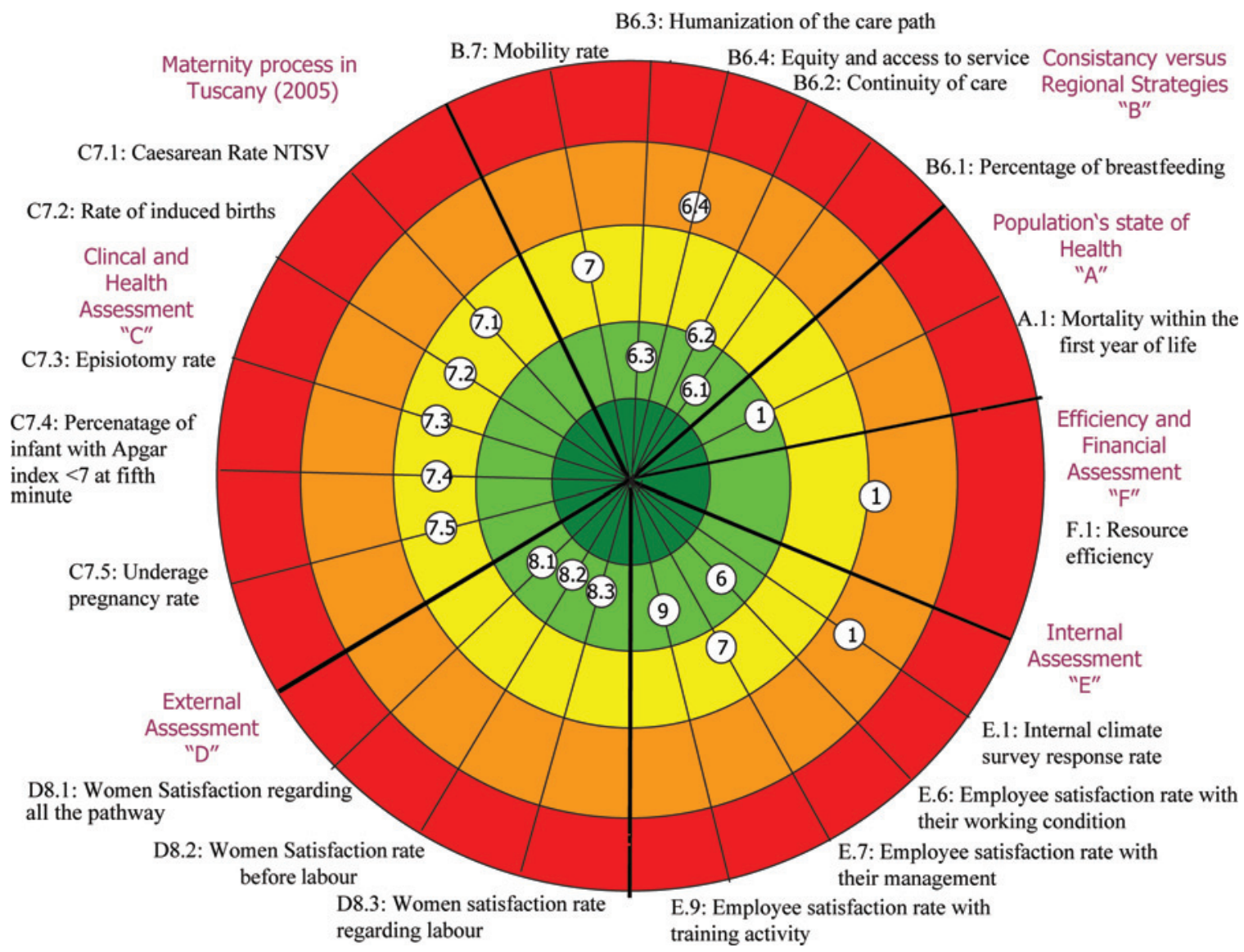

Figure 1 The target diagram of the Tuscan maternity pathway evaluation 
Table 1 The maternity path indicators

\begin{tabular}{|c|c|c|}
\hline Code of indicator & Category & Indicators \\
\hline A1 & Population's health & Mortality within the first year of life \\
\hline B6.1 & Capacity to follow regional strategies & Percentage of breastfeeding \\
\hline B6.2 & Capacity to follow regional strategies & Continuity of care \\
\hline B6.3 & Capacity to follow regional strategies & Humanization of care path \\
\hline B6.4 & Capacity to follow regional strategies & Equity and access to service \\
\hline B7 & Capacity to follow regional strategies & Mobility rate \\
\hline C7.1 & Clinical and health assessment & NTSV caesarean rate \\
\hline C7.2 & Clinical and health assessment & Rate of induced births \\
\hline C7.3 & Clinical and health assessment & Episiotomy rate \\
\hline C7.4 & Clinical and health assessment & Percentage of infant with Apgar index $<7$ at the fifth minute \\
\hline C7.5 & Clinical and health assessment & Underage pregnancy rate \\
\hline D8.1 & External assessment & Women satisfaction rate regarding all the pathway \\
\hline D8.2 & External assessment & Women satisfaction rate before labour \\
\hline D8.3 & External assessment & Women satisfaction rate regarding labour \\
\hline E1 & Internal assessment & Internal climate survey response rate \\
\hline E6 & Internal assessment & Employee satisfaction rate with the working condition \\
\hline E7 & Internal assessment & Employee satisfaction rate with their management \\
\hline E9 & Internal assessment & Employee satisfaction rate with training activities \\
\hline $\mathrm{F} 1$ & Efficiency and financial performance & Resource efficiency \\
\hline
\end{tabular}

then reviewed by professors of THs in a training programme that involved the heads of maternal and infant care departments. The indicators identified are listed in Table 1; some are combinations of a number of indicators.

\section{Data collection}

The sources of data for the different indicators were as follows (Table 2):

(a) Population health, regional register of mortality;

(b) Regional health system, the Certificati di Assistenza al Parto - certificate of birth assistance (CAP) and women's experience;

(c) Quality, the CAP;

(d) Patient satisfaction was obtained by telephone survey of women who had given birth at least 30 days previously (using the Computer-Assisted Telephone Interview methodology by the Management and Health Laboratory in collaboration with the Statistical Sector of Tuscan Region); (e) Staff satisfaction, by using the Computer-Assisted Web Interviewing methodology by the Management and Health Laboratory;

(f) Efficiency and financial performance, LHAs offices for statistics.

\section{Performance evaluation}

The benchmark for performance on each indicator was chosen in one of the following two ways:

- Ideally, by using a recognised international or regional standard, e.g. the WHO standard ${ }^{28-30}$ for the percentage of caesarean births;

- Where no obvious standard existed, the regional average was used with adjustments where necessary for different risks between health authorities.

The performance of each health authority on each indicator was scored by creating regular intervals around the benchmark.

Table 2 Data source by dimension

\begin{tabular}{|c|c|c|}
\hline Dimension & Source of data & Methodology \\
\hline Population's health & Administrative regional data & Query on regional databases \\
\hline $\begin{array}{l}\text { Capacity to follow regional } \\
\text { strategies }\end{array}$ & $\begin{array}{l}\text { Administrative regional data and patients' } \\
\text { satisfaction and experience }\end{array}$ & $\begin{array}{l}\text { Experiential items coming from the survey and query on } \\
\text { regional databases }\end{array}$ \\
\hline $\begin{array}{l}\text { Clinical and health } \\
\text { assessment }\end{array}$ & Administrative regional data & Query on regional databases \\
\hline External assessment & Patients' satisfaction and experience & $\begin{array}{l}\text { Survey through Computer-Assisted Telephone Interview } \\
\text { technique, Satisfaction items }\end{array}$ \\
\hline Internal assessment & Staff satisfaction & $\begin{array}{l}\text { Survey through Computer-Assisted Web Interviewing } \\
\text { technique }\end{array}$ \\
\hline $\begin{array}{l}\text { Efficiency and financial } \\
\text { performance }\end{array}$ & Administrative authority data & Local Health Authorities and Teaching Hospitals databases \\
\hline
\end{tabular}


The results of the implementation of the multidimensional evaluation system for the maternal and infant care pathway

The results of the PMSMP introduced in 2005, shown in the spider diagram in Figure 1, suggest that the performance was mostly good. Tuscan mothers were satisfied with the individual aspects of care in the maternal and infant care pathway both in the prenatal and delivery phases. The performance on the different dimensions was as follows:

(a) Population health, during 2002-2004 period: Tuscan mortality rate within the first year of life was 2.99 per 1000 new born alive, which was smaller than the national rate (4.04), while the rate of each LHA had great variability (from 2.00 to 4.88 per 1000 born alive); the regional performance is good (on light green band);

(b) Regional health system: Although across the region performance on average is good on Breastfeeding (B6.1), Continuity of care (B6.2) and Humanity (B6.5), there is variation with scope for improvement by some LHAs and THs (Figure 2 reports scores for each LHA). Equity and access to services (B6.4) obtains the most critical result. About $53 \%$ of pregnant women participate in the prenatal training course, but this result decreases to $16 \%$ if only women with low education are considered. A strong connection between participation and education level is observed (Figure 3);

(c) Quality: At the regional level all indicators fall into the yellow band and differences have been observed among the performances of health authorities. Figure 4 reports the variability of NTSV caesarean rate (C7.1) within LHAs and THs;

(d) Patient satisfaction: More than $90 \%$ of women stated that they were completely or very satisfied ${ }^{1}$ with the aspects related to all phases of the maternal and infant path (D8.1), the prenatal phase (D8.2), the labour phase (D8.3) and the coordination along the pathway (B6.2). Although satisfaction was very high across the region, there were statistically significant differences between LHAs, and hence scope for improvement by some (Figure 5);

(e) Staff satisfaction: The surveys of 2005 and 2007 were carried out on a representative sample of employees in all the LHAs and THs. On a regional level, training activities and professional working conditions (E9 and E6) were assessed positively, but the employee satisfaction with their management (E7) obtained an intermediate assessment. The percentage of employees who work in the maternal and infant sector who took part in the survey was very low and points out a higher difficulty to participate. This is confirmed by comparing the response rate of the rest of the employees with that of the maternal and infant professionals as shown in Figure 6;

(f) Efficiency and financial: The relationship between human resources engaged within the maternal infant care pathway and the services delivered results different among the LHAs. In Tuscany each gynaecologist follows a mean of 91.83 deliveries per year (Figure 7). LHAs under the mean were considered less efficient and they obtained a lower score.

It is interesting to note that there is a significant correlation between the high level of efficiency (number of deliveries per gynaecologist) and the good performance on the clinical dimension (NTSV caesarean rate) $(P<0.05)$, such as achieved by the LHA 4 and LHA 5. This proves that resource volume is not related to the quality of care.

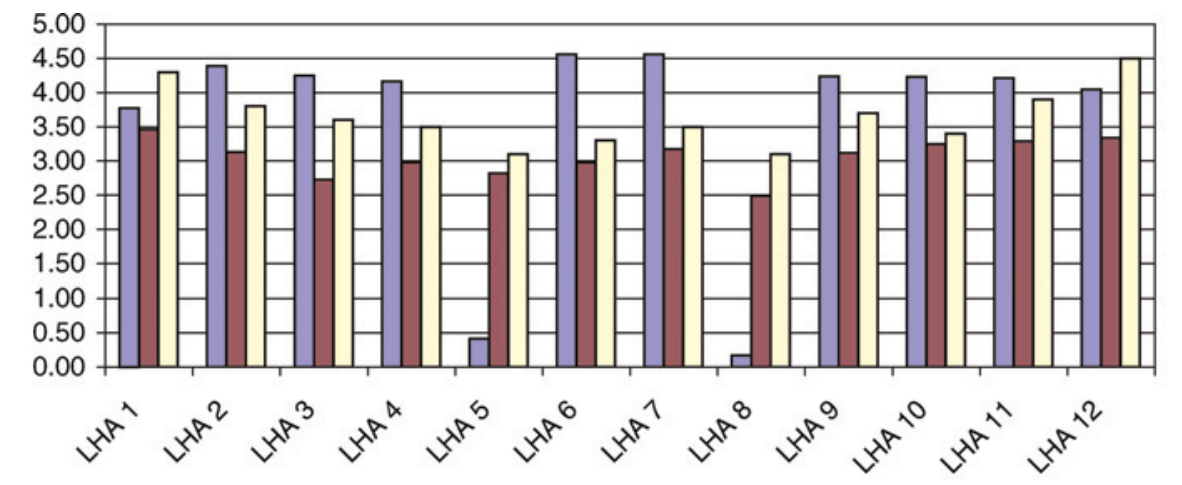

$\square$ B6.1: Percentage of breastfeeding $\square$ B6.2: Continuity of care $\square$ B6.3: Humanization of care path

Figure 2 The performance scores of the indicators of B dimensions coming from the survey within Local Health Authorities (LHAs)

\footnotetext{
${ }^{1}$ Women could have chosen among five modalities of answers: completely satisfied; very satisfied; fairly satisfied; little satisfied; and not satisfied at all.
} 
$\square$ Yes $\square$ No

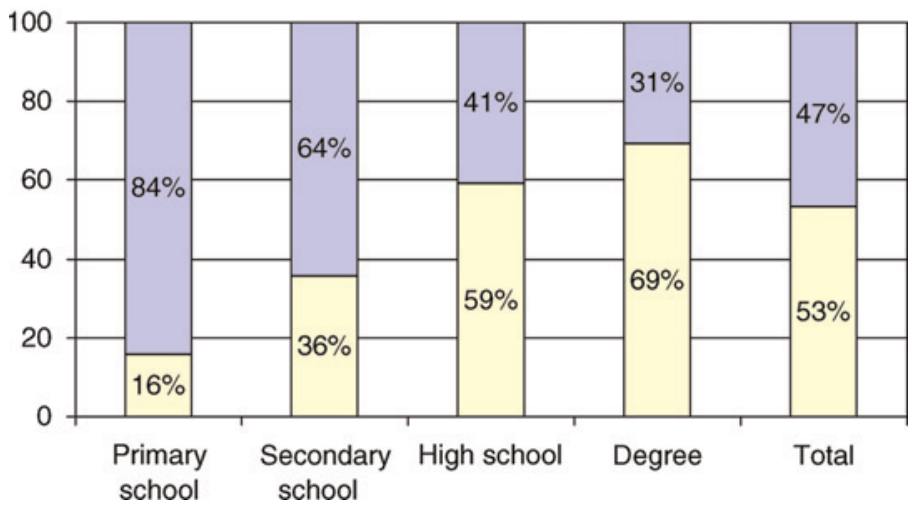

Figure 3 The distribution of the access to prenatal course by the educational qualification of the mothers in a Local Health Authority (indicator B6.4)

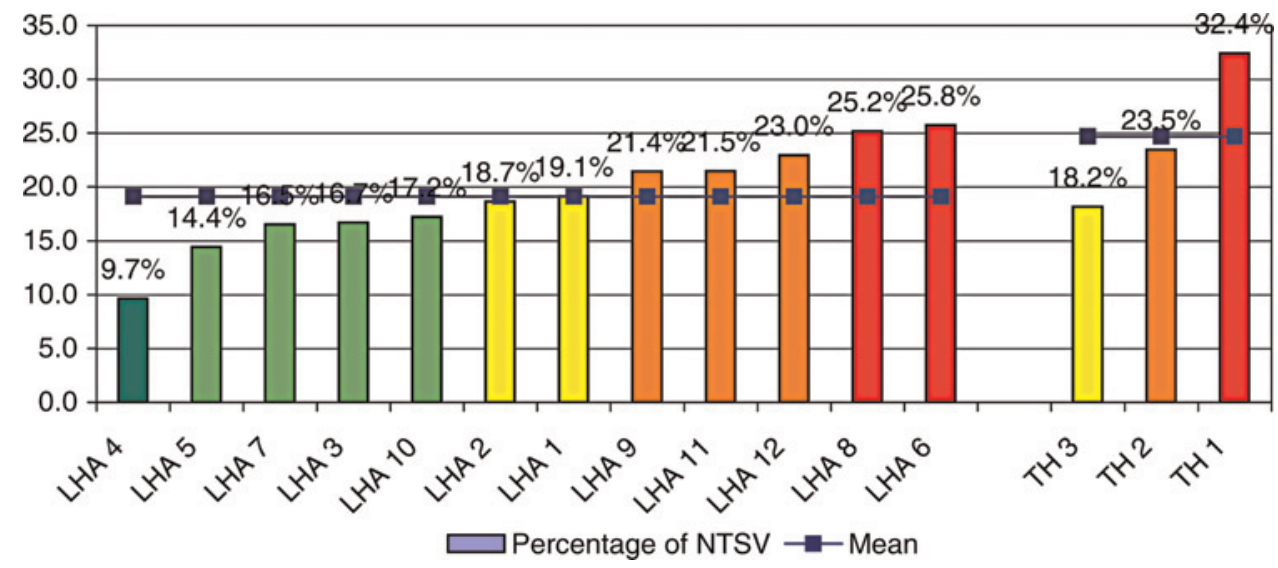

Figure 4 The distribution of the Nullipar Terminal Single Vertex (NTSV) caesarean rate among Local Health Authorities (LHAs) and Teaching Hospitals (THs)

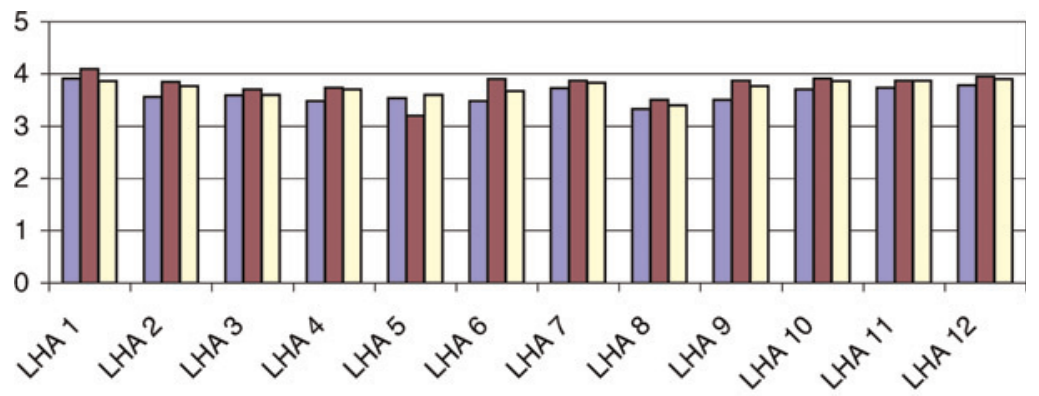

$\square$ D8.1: Women satisfaction rate regarding all the pathway

口 D8.2: Women satisfaction rate before labour

口D8.3: Women satisfaction rate regarding labour

Figure 5 The mean satisfaction of maternal infant path phases within Local Health Authorities (LHAs) 


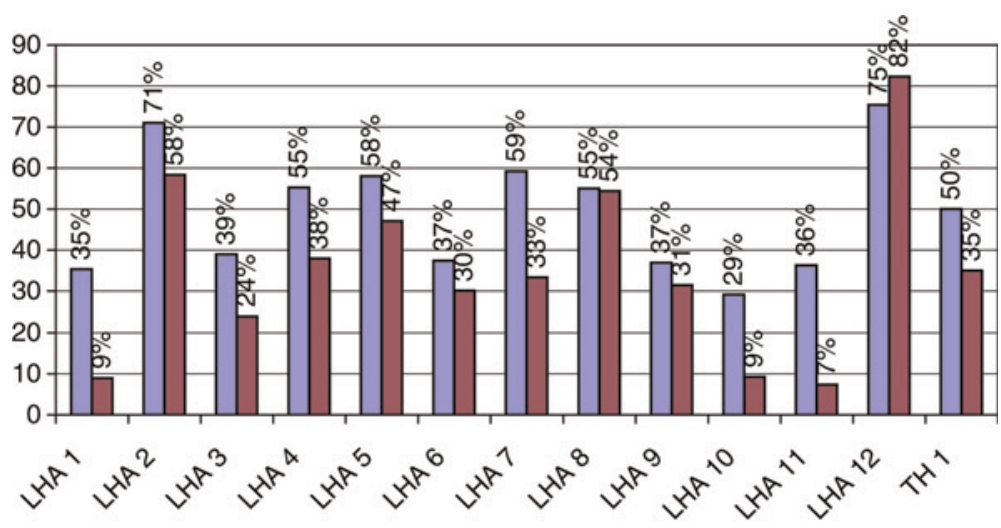

$\square$ Overall response rate $\square$ Maternal and infant path response rate

Figure 6 The response rate of the climate survey of both the overall and maternity path

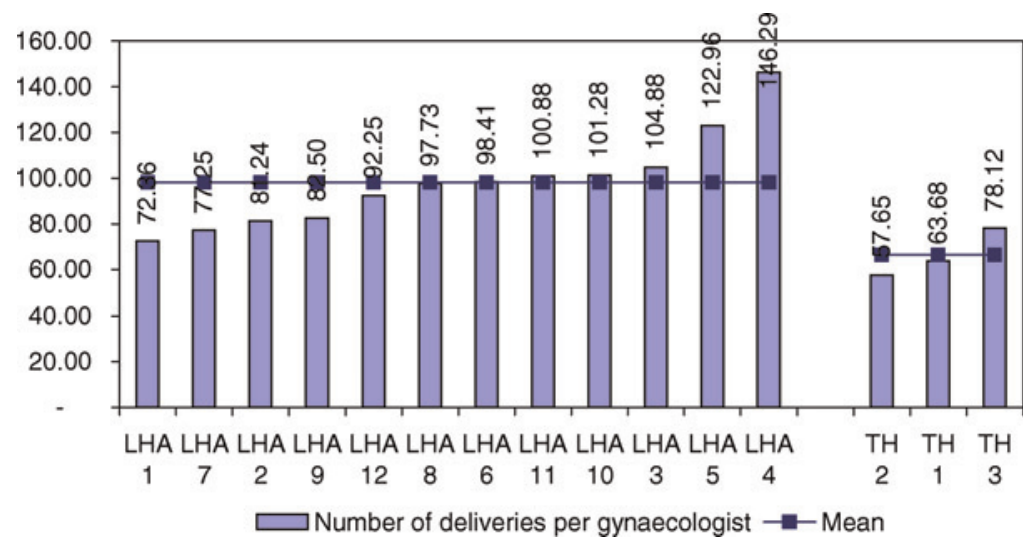

Figure 7 The distribution of the number of deliveries per gynaecologist among Local Health Authorities (LHAs) and Teaching Hospitals (THs)

\section{Discussions and conclusions}

The application of this multidimensional evaluation system to the maternity pathway has been well accepted and it is now used in the local budget systems by the health care professionals and managers in Tuscany. What has facilitated the introduction of the system was that for the first time in Tuscany it was possible to integrate data from the regional information system and field surveys considering performance in various dimensions, and that they were presented in benchmarking.

A second point that helped the introduction of the system was the easy and effective way through which data are reported and presented visually. The target and its colours have become a common language among obstetricians, physicians, nurses and managers. It also represents a friendly way through which health care results are communicated to the public.

All LHA managers, the regional councillor and all health care professionals receive a booklet and can explore the indicators and analyse the relationship between the results obtained on the web (see www.valutazionesanitatos cana.sssup.it). Some of the indicators, such as the continuity of care and the NTSV caesarean rate, are also linked to the incentive system for the general managers of the LHAs.

The above-mentioned issue and the data public release had an impact on the quality of the service delivered, especially in the LHAs who performed badly. ${ }^{31}$ These LHAs adopted actions to improve their performance and to organize training courses involving obstetricians, physicians and nurses working both in the hospital and in primary care services.

Through PMSMP it has also been possible to identify and highlight at which level of the regional health system problems exist. If a particular indicator shows a negative performance for all the health authorities, it is a general problem that requires attention at a regional level. If, however, there is variability between the health authorities, it means that health authorities can improve considering the best practice.

Health authorities with less favourable results tend to look at those who perform well in specific areas and adopt similar more effective and efficient strategies. ${ }^{32}$

The system represents a rich assessment tool for the regional council, especially because it is used systematically. It supports the regional government in setting 
health care priorities and allocating funds to assure a high quality of care.

However, there are still many areas to be investigated and improved. Although not perfect, the Tuscan PMSMP gives a real picture of the quality of care of the pathway; it highlights the strengths and weaknesses of each single LHA in the different areas. Future research should investigate the main levels through which improved performance can be realized and the relationship among the various indicators.

\section{Acknowledgements}

We thank all staff of the Management and Health Laboratory for improving a positive learning environment despite hard work. Special thanks to Sara Barsanti, Alessandro Campani, Domenico Cerasuolo, Elisabetta Felloni, Barbara Lupi, Cristina Renzi and Daniel De Wett.

\section{References}

1 Constitution of the World Health Organization, Article 2. Geneva: World Health Organization, 1948

2 United Nations Universal Declaration of Human Rights. New York, NY: United Nations, 1948

3 Human Development Report 2003. Millennium Development Goals: A Compact Among Nations To End Human Poverty. New York, NY: Oxford University Press for the United Nations Development Programme, 2004

4 WHO, The World Health Report 2005. Make Every Mother and Child Count. WHO, 2005

5 Minestero della Salute. National Health Plan (Piano Sanitario Nazionale) 1998-2001

6 Regional Health Plan of Tuscany (Piano Sanitario Regionale Toscana) 1998-2001

7 Regional Health Plan of Tuscany (Piano Sanitario Regionale Toscana) 2002-2004

8 Regional Health Plan of Tuscany (Piano Sanitario Regionale Toscana) 2005-2007

9 Delibera Giunta Regionale Toscana n. 555 of 2004

10 Delibera Giunta Regionale Toscana n. 784 of 2004

11 Nuti S, Il sistema di valutazione delle aziende sanitarie toscane, in S. Baraldi (a cura di) Balanced Scorecard nelle aziende sanitarie. Milano: McGraw Hill, 2005

12 Laboratorio Management e Sanità, Report 2006. Il sistema di valutazione della performance della sanità toscana. Edizioni ETS, 2007

13 Lewis J. The EFQM Excellence Model. London: Woodward Lewis, 1999
14 Mayne J, Zapico Goni E. Effective Performance Monitoring: A Necessary Condition for Public Sector Reform Monitoring Performance in the Public Sector. New Jersey: Transaction Publishers, 1997

15 Kaplan RS, Norton DP. Putting the balance scorecard to work. Har Bus Rev 1993;71:134-47

16 Canadian Institute for Health Information, Government Hospital Association and the University of Toronto. Hospital Report '99: A Balanced Scorecard for Ontario Acute Care Hospitals. Toronto: Ontario Hospital Association, 1999

17 Pink GH, McKillop I, Schraa EG, Preyra C, Montgomery C, Baker R. Creating a balanced scorecard for hospital system. Health Care Finan 2001;27:1-20

18 Canadian Institute for Health Information. The Ontario Health System Scorecard. Health Results Team for Information Management. Queen's Printer for Ontario, 2006

19 Kaplan RS, Norton DP. The Balanced Scorecard: Translating Strategy into Action. Cambridge MA: Harvard Business School Press, 1996

20 Kaplan RS, Norton DP. Using the balanced scorecard as a strategic management system Har Bus Rev 1996;74:75-85

21 Kaplan RS, Norton DP. Linking the balanced scorecard to strategy. California Manag Rev 1996;4:53-79

22 Pursglove J, Simpson M. A balanced scorecard for university research. In: Neely A ed. Performance Measurement: Past Present and Future. Cransfield: Cransfield School of Management, 2000

23 Aidemark LG. The meaning of balanced scorecards in the healthcare organization. Financ Account Manag 2001;17:23-40

24 Abernethy MA, Stoelwinder JU. The role of professional control in the management of complex organizations. Account Organ Soc 1995;20:1-17

25 Jones CS, Dewing IP. The attitudes of NHS clinicians and medical managers towards changes in accounting controls. Financ Account Manag 1997;13:261-80

26 Health Canada, Health Policy and Communication. Canada Health Act Division, Canada Health Act, Annual Report, 2001

27 Sutter Women's \& Children's Services. First Pregnancy and Delivery. Clinical Iniziative Resources. California: Sutter Health, 2001

28 WHO. Appropriate technology for birth. Lancet 1985;2:436-7

29 WHO Department of Reproductive Health and Research. Care in Normal Birth: A Practical Guide. Report of a Technical Working Group. WHO/FRH/MSM/96.24. Geneva: WHO, 1996

30 Department of Reproductive Health and Research. WHO Antenatal Care Randomized Trial: Manual for the Implementation of the New Model. WHO/RHR/01.30. Geneva: WHO, 2002

31 Bevan G, Hood C. What's Measured is What Matters: Targets and Gaming in the English Public Health Care System. In: Public Administration, Vol. 84, 2006a

32 Mc Nair CJ, CMA, Leifried KHJ. Benchmarking: A Tool for Continuous Improvement. New York USA: John Wiley \& Sons, 1992 